\title{
The Debate of Environmental Impact and Tourism Development: Perspective from Local Resident and Businessman
}

\author{
Chao, Chen-Wei \\ Ph. D. Student, Department of Urban Planning, \\ National Cheng Kung University, Tainan, Taiwan \\ Shyr, Oliver F. \\ Associate Professor, Department of Urban Planning, \\ National Cheng Kung University, Tainan, Taiwan \\ Lee, Ching-Sung \\ Professor, Department of Restaurant, Hotel and Institutional Management, \\ Fu Jen University, New Taipei, Taiwan \\ Chao, Chen-Huang \\ Graduate student, Department of Life Science, \\ National Taiwan Normal University, Taiwan
}

Tsai, Li

College student, Department of Restaurant, Hotel and Institutional Management, Fu Jen University, New Taipei, Taiwan

Kang, Chih-Sheng

Ph. D. Student, Graduate school of policy and management, Technology \& innovative management, Doshisha University, Japan. Email: fjkangjason@gmail.com

Doi:10.5901/mjss.2013.v4n10p410

\section{Abstract}

The purpose of the research is to examine that the benefit and cost of tourism development based on its feature industry in Yingge. The questionnaire survey is used on the study that attempts to find the relation of tourism development and tourism impact. The result points out that Yingge populations accept ceramics as the most representative industry, and recognized its development with tourism. The ceramic feature with tourism development in Yingge includes diversification, creative life, and art. Tourism development brought benefits with a creation of employment, increased in revenue, improvement of facility and infrastructure, increased local pride and community spirit, promotion of local culture, and improvement of destination image. Concomitant negative impacts resulted from tourism development also result in environmental damage, life disturbance, traffic congestion, and ecological devastation. The study provides references for other similar regions eager to boost economic growth and industrial development.

Keywords: local feature industry; tourism development; benefit and cost

\section{Introduction}

Local economic development aims to keep local economy from declining and falling through economic development in which the industry plays an essential role (Yuan, Wang, \& Chiou, 2007). Around the world, tourism has been turned into an important tool for regional economic growth and development (Elliot, 1987). The growth of the tourism industry has had significant impact on the economic development of related industries. This phenomenon is well documented in the 
literature that local feature industry associated with tourism industry could promote local economic growth, create employment opportunities, solve the problem of unemployment and enhance the quality of life. Unfortunately, today's inorganic development is actually detrimental to communities (Sirakaya, Jamal, \& Choi, 2001). The rapid growth in the tourism industry with unplanned tourism development would ultimately lead environmental degradation (Green, Hunter, \& Moore, 1990), and socio-economic imbalance amongst local populations (Edelmann, 1975). Such impacts challenge local governments, planners, and researchers to rethink current feature industry tourism development.

In discussions regarding regional development, the notion that people-centred initiatives is needed. The existing literature suggests that good will and cooperation of host communities is one of the essential elements of community development (Murphy, 1985). Local populations are mainly victory (beneficiary) or victim of tourism development. Despite a number of research studies being conducted on tourism development with local feature industry, few have focused on local populations' perceptions. Eisinger (2000) also points to the negligence of civic leaders and politicians who boost tourism and entertainment projects to build cities for visitors rather than paying attention to local residents. Given the fact that local feature industry combining tourism development can flourish in an area only with the support of the area's populations, it is envisaged that the perceptions of local populations toward tourism development serve as crucially important inputs in identifying the strategic and managerial priorities. Focusing on local populations' responses, this study seeks to identify both benefit and cost of tourism development, with the case of ceramics in Yingge. Furthermore, this study examines the local populations' perception difference on development impact, with more specific on local resident and businessman.

\section{Methodology}

The purpose of this study was to identify the benefit and cost of tourism development in Yingge area, and further examine the perception difference between local resident and businessman. The researchers conducted a questionnaire survey and semi-structured questionnaire was used to collect empirical data in the current study. The questions in the questionnaire were based on information obtained from reviewing the existing literature, and the questionnaire was pretested and revised. The content of questionnaire includes personal data, perceived feature of the ceramic industry, and perceived impact of tourism development. The respondents were asked to rate the perceived ceramic feature with tourism development and the perceived impact of tourism development using a five-point Likert scale, which in this case ranged from 'strongly disagree $(=1)$ ' to 'strongly agree $(=5)$ '. The survey was conducted from September to November 2006 in Yingge in Taiwan.

In keeping with the research purpose of this study, one part of participants in the survey was local residents whose age is over 15 and had lived in Yingge area over half years. We conducted systematic sampling based on the proportion of population in Yingge area, and selected residents with long-term life experience (over half year) as candidate samples. Respondents with long-term life experience are more likely to have a comprehensive understanding of the nature of Yingge area. Five hundred questionnaires were distributed to local residents, yielding 463 usable surveys. The valid response rate was $92.6 \%$. The other part of participants in the survey was local businessman in the historic ceramic street. Census survey was conducted that total 130 shops were operated in the historic ceramic street. Researchers and academic colleagues personally visited the shop owners or clerks to increase the response rate and ensure the accuracy of the questionnaire collection. Deducting those who refuse to participate in investigation, 73 usable surveys was yielded.

\section{Results}

Table 1 illustrates the perceived development of Yingge area between local resident and businessman. Both residents and businessmen consider Yingge to be cultural district, and think the ceramics is the most representative feature industry of Yingge. The main tourism resources are also related to ceramics, including the historic ceramic street and ceramics museum.

Table 1. Perceived development between local resident and businessman (\%)

\begin{tabular}{lccc}
\hline & Local resident $(\mathrm{n}=463)$ & Local businessman $(\mathrm{n}=73)$ & $\chi^{2}$ \\
\hline The district position of Yingge & 48.38 & & \\
Cultural district & 17.49 & 63.01 & $11.53^{*}$ \\
Residential district & 9.94 & 4.11 & \\
Industrial district & 16.41 & 5.48 & \\
Commercial district & & 19.18 & \\
\hline
\end{tabular}




\begin{tabular}{lccc}
\hline Others & 7.78 & 8.22 & \\
\hline Ceramics is the most representative industry in Yingge & & $7.75^{\star}$ \\
Agree & 90.28 & 100.00 & \\
Disagree & 4.54 & 0.00 & \\
No comment & 5.18 & 0.00 & $35.27^{* *}$ \\
\hline Tourism resource for tourist in Yingge (multi-select) & & 3.04 \\
Natural landscape & 57.88 & 20.55 & 0.70 \\
Cultural landscape & 36.50 & 26.03 & $7.34^{\star *}$ \\
Historic ceramic street & 90.06 & 93.15 & $11.10^{* *}$ \\
Ceramics museum & 83.15 & 69.86 & $28.57^{* *}$ \\
Local famous temple & 22.25 & 5.48 &
\end{tabular}

The researchers employed an exploratory factor analysis to extract the dimensions of the ceramic feature and the impact of tourism development with the survey data. Ceramic feature with tourism development were identified based on the attribute covered: diversification, creative life, and art. Additionally, benefit identified based on the attribute covered: employment opportunity, local revenue, facility and infrastructure, local pride and community spirit, culture promotion, and destination image; Cost factor were also identified, including environmental protection, life quality, traffic order, and ecological resource. A reliability test based on Cronbach's a score was used to test whether these factors are consistent and reliable. Cronbach's a for each factor are shown in Table 2. The reliability value of each factor is greater than 0.6, which is considered adequate for a satisfactory level of reliability in basic research.

Table 2. Factor analysis of ceramic feature and tourism impact

\begin{tabular}{|c|c|c|c|}
\hline Factors & $\begin{array}{l}\text { Factor } \\
\text { Loadings }\end{array}$ & $\begin{array}{c}\text { Variance } \\
\text { explained (\%) }\end{array}$ & \\
\hline Ceramic feature with tourism development & & 58.55 & 0.63 \\
\hline Diversification & 0.83 & & \\
\hline Creative life & 0.78 & & \\
\hline Art & 0.67 & & \\
\hline Benefit & & 42.29 & 0.72 \\
\hline Employment opportunity & 0.68 & & \\
\hline Local revenue & 0.66 & & \\
\hline Facility and infrastructure & 0.65 & & \\
\hline Local pride and community spirit & 0.64 & & \\
\hline Culture promotion & 0.63 & & \\
\hline Destination image & 0.63 & & \\
\hline Cost & & 56.53 & 0.74 \\
\hline Environmental protection & 0.79 & & \\
\hline Life quality & 0.77 & & \\
\hline Traffic order & 0.74 & & \\
\hline Ecological resource & 0.71 & & \\
\hline
\end{tabular}

Table 3 presents the perceived difference between local residents and businessmen. In discussing with regard to the benefit, local businessmen reveal more agreement of employment and income benefit from tourism development than local residents. However, local residents reveal more approve of the culture promotion from tourism development than local businessmen. As for the cost, local businessmen have stronger feeling about the environmental damage and traffic congestion than local residents as result of tourism development.

Table 3. Perceived feature and tourism impact between resident and businessman

\begin{tabular}{llccccc}
\hline \multirow{2}{*}{ Factors } & Items & \multicolumn{3}{c}{ Resident } & \multicolumn{3}{c}{ Businessman } \\
& & Mean & Std. & Mean & Std. & deviation \\
& & & deviation & $t$ \\
Ceramic & Diversification & 4.95 & 1.61 & 4.24 & 1.49 & $-4.86^{\star \star}$ \\
Feature & Creative life & 4.87 & 1.60 & 3.76 & 1.61 & $-2.00^{\star}$ \\
& Art & 3.88 & 1.99 & 2.94 & 1.78 & -0.92 \\
\hline
\end{tabular}




\begin{tabular}{|c|c|c|c|c|c|c|}
\hline \multirow{6}{*}{ Benefit } & Employment opportunity & 3.63 & 0.89 & 2.77 & 0.91 & $-2.02^{\star}$ \\
\hline & Local revenue & 3.44 & 0.99 & 3.81 & 0.98 & $-2.93^{\star *}$ \\
\hline & Facility and infrastructure & 3.70 & 0.85 & 2.72 & 0.86 & 0.65 \\
\hline & Local pride and community spirit & 3.81 & 0.77 & 2.63 & 0.86 & -0.08 \\
\hline & Culture promotion & 4.08 & 0.64 & 2.77 & 0.73 & $2.50^{*}$ \\
\hline & Destination image & 4.03 & 0.69 & 2.89 & 0.64 & -0.28 \\
\hline \multirow{4}{*}{ Cost } & Environmental protection & 2.96 & 1.09 & 2.38 & 1.04 & $-2.68^{* *}$ \\
\hline & Life quality & 2.98 & 1.11 & 1.96 & 0.94 & 1.63 \\
\hline & Traffic order & 3.67 & 1.05 & 2.86 & 0.85 & $-3.02^{\star \star}$ \\
\hline & Ecological resource & 2.92 & 0.98 & 2.11 & 0.99 & -0.33 \\
\hline
\end{tabular}

The researchers further conduct structural equation modeling to test the full model of ceramic feature, benefit, and cost by using several latent variables. The measurement model of ceramic feature hypothesizes that the ceramic feature constitutes an exogenous latent variable that can be represented by three exogenous measured variables: diversification, creative life, and art. Additionally, the measurement model of benefit used here hypothesizes that the benefit is an endogenous latent variable that can be represented by four endogenous latent variables, including employment opportunity, local revenue, facility and infrastructure, local pride and community spirit, culture promotion, and destination image. The measurement model of cost used here hypothesizes that the cost is an endogenous latent variable that can be represented by four endogenous latent variables, including environmental protection, life quality, traffic order, and ecological resource. Following the measurement model, the researchers conducted confirmatory factor analysis to measure the properties of the scales. The estimation of variables in this study was tested using maximum likelihood methods to determine whether the model fit the structural equation models. The structured factors used in this study are shown in Figure 1. The full SEM model fit well : X2 (63) $=3.19, \mathrm{GFI}=0.965, \mathrm{AGFI}=0.92$, and NFI=0.86. As a result, the model fit corresponded with the estimation standards of an SEM model, and the reliability and validity of this study were judged to be satisfactory. The structured factor of ceramic feature for benefit was significant at 0.33 $(p<0.001)$, and for cost was significant at $-0.19(p<0.01)$. Therefore, ceramic feature with tourism development have significant positive impacts on the benefit, and have significant negative impacts on the cost.

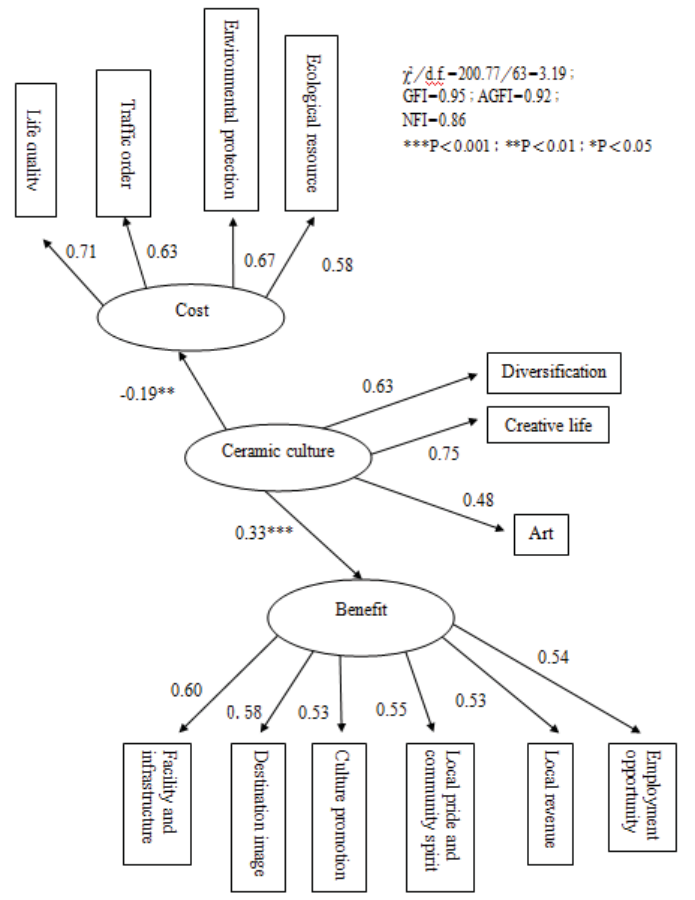

Fig. 1. Path model of ceramic culture, benefit, and cost 


\section{Conclusion}

The development of local feature industries has shifted from the concept of preserving traditional cultural assets, using region-specific unique resources, integrated with government policies and creative activities, to nourish industries representative of the region. This paper examines the impact of local feature industry combining tourism development derived from current regional development case- Yingge. Findings suggested that tourism development in the Yingge has contributed both benefit and cost to local populations. Tourism development brought more benefits with a creation of employment, increased in revenue, improvement of facility and infrastructure, increased local pride and community spirit, promotion of local culture, and improvement of destination image. Concomitant negative impacts resulted from tourism development also result in environmental damage, life disturbance, traffic congestion, and ecological devastation. Considering ceramics was approved as representative industry for both local residents and businessmen, there is needed to construct a balance between benefit and cost of tourism development. Consequently, the study provides references for other similar regions eager to boost economic growth and industrial development.

\section{References}

Edelmann, K.M.F. (1975). Major problems of tourism growth in developing countries. Annals of Tourism Research, 3(1), 33-45.

Eisinger, P. (2000). The politics of bread and circuses: Building the city for the visitor class. Urban Affairs Review, 35(3), 316-333.

Elliot, J. (1987). Government management of tourism: A Thai case study. Tourism Management, 8(2), 223-234.

Green, H., Hunter, C., \& Moore, B. (1990). Assessing the environmental impact of tourism development: Use of the Delphi technique. Tourism Management, 11(2), 111-125.

Murphy, P. E. (1985). Tourism: A Community Approach. NY: Methuen.

Sirakaya, E., Jamal, T., \& Choi, H.S. (2001). Developing tourism indicators for destination sustainability. In D. B. Weaver (Ed.), The encyclopedia of ecotourism (pp. 411-432). NY: CAB International.

Yuan, B., Wang, Y.W., \& Chiou, T.P. (2007). The development framework of local feature industry in Asia- From start-ups to innovative development. Asia Pacific Journal of Innovation and Entrepreneurship, 1(1), 1-20. 